\title{
Rapid disappearance of left ventricular mass (presumed thrombus) in a patient with cardiomyopathy
}

\author{
JULIEN BENSAID, PATRICK BLANC, PATRICE VIROT \\ From Service de Cardiologie, Hôpital Universitaire Dupuytren, Limoges, France
}

SUMMARY A man aged 41 years with a clinical diagnosis of cardiomyopathy and hepatic insufficiency was found, on angiocardiography, to have a mass, presumably a thrombus, within the left ventricle. A second angiocardiogram performed five days later showed that the thrombus had disappeared. The mechanism invoked was more probably an increase of spontaneous fibrinolysis as described in cirrhotic patients, perhaps helped by heparin, rather than ejection of the mass from the ventricle with silent embolisation somewhere in the systemic circulation.

The detection of a left ventricular mass in vivo may be made by angiocardiography. Two dimensional echocardiography is, however, the best and the most sensitive technique. A left ventricular mass is usually a thrombus but occasionally a tumour. We report a patient with congestive cardiomyopathy in whom a left ventricular mass apparently disappeared within five days of its detection by angiocardiography.

\section{Case report}

A 41-year-old man, a labourer, was admitted to hospital on 24 August 1979, because of congestive heart failure. There was a past history of heavy alcohol ingestion and laboratory data showed hepatic insufficiency (Table 1). The blood pressure was 110/ $70 \mathrm{mmHg}$, pulse regular at $116 / \mathrm{min}$, and temperature normal. The erythrocyte sedimentation rate was $3 \mathrm{~mm}$ in one hour. There was venous distension and oedema of both legs. Basal rales were heard in the chest. There was a faint systolic murmur $1 / 6$ at the apex. The heart was enlarged on chest radiography (cardiothoracic ratio 0.62). The electrocardiogram showed sinus tachycardia with left ventricular hypertrophy and left bundle-block branch. An M-mode echocardiogram recorded at the fourth intercostal space at the left sternal edge showed dilatation of the left ventricular cavity with an end-diastolic dimension of $6 \mathrm{~cm}$ and a very hypoactive interventricular septum. The patient was regarded as having congestive cardiomyopathy. He was given digitalis and diuretics and the result was good.

Cardiac catheterisation on 31 August 1979 (Table 2) showed an increase of both right and left ventricular end-diastolic pressures. The cardiac index was 2.4 $1 / \mathrm{min}$ per $\mathrm{m}^{2}$, left ventricular end-diastolic volume was $182 \mathrm{ml} / \mathrm{m}^{2}$, and the ejection fraction was 0.21 .

Selective left ventricular cineangiography in the right anterior oblique projection disclosed dilatation and considerable hypokinesia of the left ventricle. In addition, angiography showed a mobile left ventricular filling defect at the apex during diastole moving

Table 2 Cardiac catheterisation data

\begin{tabular}{lcc}
\hline & $\begin{array}{l}\text { Pressure (mmHg) } \\
\text { Systolic/diastolic }\end{array}$ & Mean \\
\hline Right atrium & $17 / 9$ & 13 \\
Right ventricle & $55 / 16$ & - \\
Main pulmonary artery & $55 / 32$ & 40 \\
-Wedge pressure & $38 / 23$ & 30 \\
Left ventricle & $120 / 35$ & 100 \\
Aorta & $120 / 90$ & 100 \\
\hline
\end{tabular}

Table 1 Laboratory data

\begin{tabular}{|c|c|c|c|c|c|c|c|c|}
\hline $\begin{array}{l}\text { Albumin } \\
(\mathrm{g} / \mathrm{l})\end{array}$ & $\begin{array}{l}\text { Alkaline } \\
\text { phosphatase }\end{array}$ & $\underset{(U / m l)}{A S T^{\star}}$ & $\begin{array}{l}A L T^{\star} \\
(U / m l)\end{array}$ & $\begin{array}{c}\gamma G T^{\star} \\
(U / m l)\end{array}$ & $\begin{array}{l}B S P \star \\
\text { retention } \\
(\%)\end{array}$ & $\begin{array}{l}\text { Prothrombin } \\
\text { time } \\
(\%)\end{array}$ & $\begin{array}{l}\text { Total } \\
\text { cholesterol } \\
(\text { mmol/l)† }\end{array}$ & $\begin{array}{l}\text { Bilirubin } \\
(\mu \mathrm{mol} / \mathrm{l}) \dagger\end{array}$ \\
\hline 36 & 12 & 41 & 62 & 74 & 100 & 60 & 2.7 & $6 \cdot 84$ \\
\hline
\end{tabular}

^Abbreviations: AST, serum aspartate aminotransferase; ALT, serum alanine aminotransferase; $\gamma \mathrm{GT}$, gamma glutamyl transferase (normal value $<40$ ); BSP, bromsulphophthalein.

†Conversion from SI units to traditional units: cholesterol $1 \mathrm{mmol} / 1 \approx 38.6 \mathrm{mg} / 100 \mathrm{ml} ; \mathrm{bilirubin} 1 \mu \mathrm{mol} / \mathrm{l} \approx 0.058 \mathrm{mg} / 100 \mathrm{ml}$. 
toward the aortic valve in systole (Fig. 1). The size of the defect was $2.5 \times 1.5 \mathrm{~cm}$. The patient was considered to have a left ventricular thrombus rather than a left ventricular tumour. Heparin was given intravenously at the rate of $40 \mathrm{mg}$ ( $4000 \mathrm{IU}$ ) every three hours and surgical treatment was planned. Before this, however, a further cineangiogram was taken on 5 September 1979. It was surprising to see that the left ventricular filling defect had disappeared (Fig. 2). The patient had not shown peripheral or cerebral emboli. Selective coronary arteriography was normal. The patient was discharged home on 9 September 1979. He was seen four, eight, and 12 months later
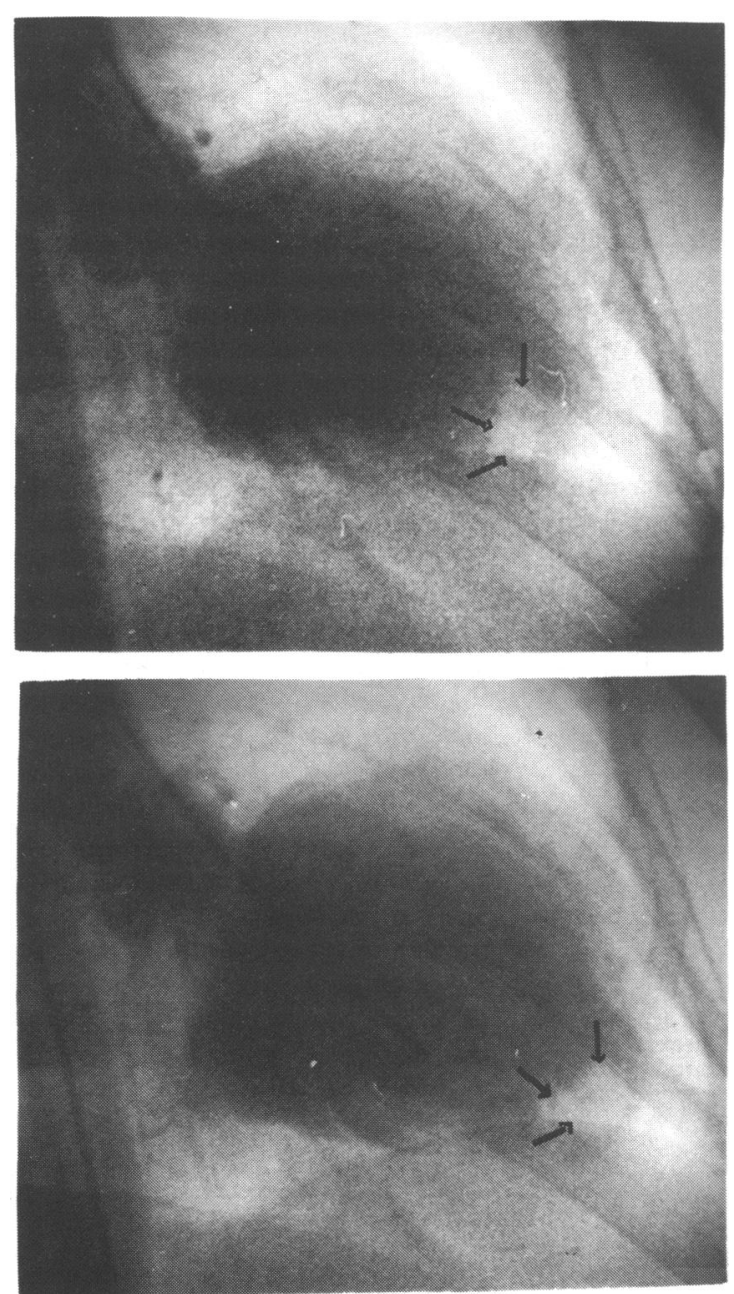

Fig. 1 First cineangiography performed on 31 August 1979. Left ventriculogram in the right anterior oblique projection, in systole (top) and diastole (bottom). Note the filling defect at the apex of left ventricle. and was reasonably well, taking anticoagulanttherapy, digitalis, and diuretics.

\section{Discussion}

The left ventricular mass was considered to be $\frac{\overline{\bar{T}}}{\frac{7}{4}}$ thrombus particularly because the underlying diseas ${ }^{2}$ was a cardiomyopathy. Left ventricular thromb occur frequently in cardiomyopathies, with an inci dence of 25 to $50 \%$ of necropsied patients according to Perrin et al. ${ }^{1}$ and Reeder et al. ${ }^{2}$

The disappearance of this mass, recognised five days after anticoagulant treatment, can be explained

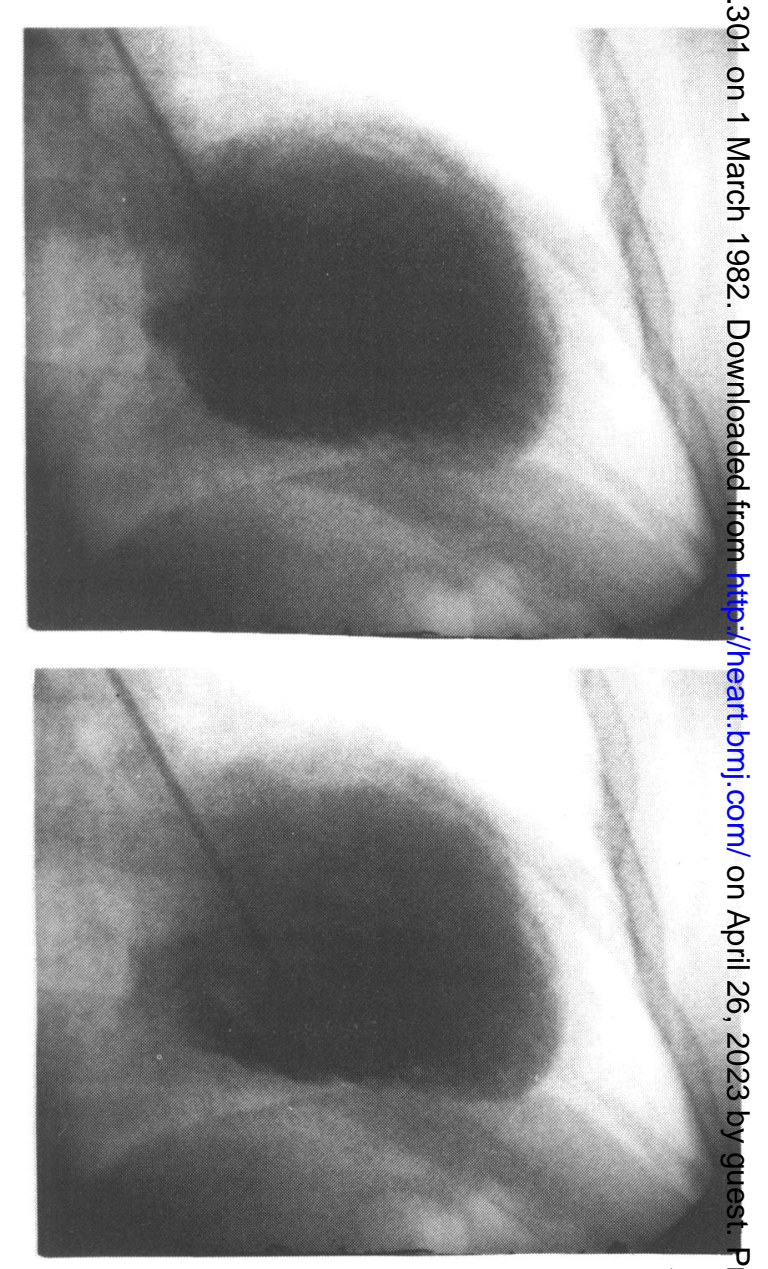

Fig. 2 Second cineangiography performed on 5 September 1979. Left ventriculogram in systole (top) and diastole (bottom Note the disappearance of the filling defect. The similar

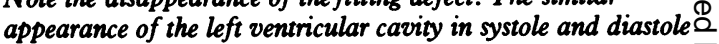
indicates severe generalised hypokinesia, presumably a result of cardiomyopathy. 
in one of two ways. The first is expulsion from the ventricle to produce silent embolisation somewhere in the systemic circulation. Miller et al. ${ }^{3}$ have reported several cases of silent emboli, especially involving the spleen or kidneys in acute and in healed myocardial infarction. The second explanation which seems the more probable is lysis of the thrombus. According to Fletcher $e t a l .{ }^{4}$ and to Pises et al. ${ }^{5}$ disappearance of the thrombus could be explained by increased spontaneous fibrinolysis. Our patient had severe hepatic insufficiency and these authors ${ }^{4} 5$ showed abnormally active fibrinolysis in cirrhotic patients, probably the result of failure of hepatic clearance mechanisms for plasminogen activator.

Other cases of disappearance of left ventricular thrombi have been previously reported. ${ }^{67}$ Mikell $e t$ al. ${ }^{6}$ have followed 15 patients, eight with chronic cardiomyopathy and seven with recent myocardial infarction, in whom left ventricular thrombi were discovered. They performed serial two dimensional echocardiograms, 33 to 240 days after initial examination. In the nine patients who received anticoagulation for at least 30 days, left ventricular thrombi resolved in five cases, decreased in size in two cases, and remained unchanged in two cases. No patient had clinically apparent emboli. In the six patients who did not receive anticoagulant treatment, the left ventricular thrombi remained apparently unchanged in five cases, and the size of the thrombus decreased in one case; two patients had emboli. Meltzer et al., ${ }^{7}$ also using serial two dimensional echocardiograms, found a reduction in size of left ventricular thrombi at 10 month follow-up in two patients, and in one of them the mass had disappeared after 19 months.

According to these reports and in view of our own case we suggest that when a left ventricular mass is discovered in patients with cardiomyopathy, anticoagulant treatment should be given and surgical treatment may be delayed. Serial two dimensional echocardiograms are advised to follow the size of the intraventricular mass. If echocardiography does not show the mass, then a second angiocardiogram may be considered before surgical intervention is advised.

The authors wish to thank $\operatorname{Dr}$ R G Grainger of Sheffield for his help.

\section{References}

1 Perrin A, Loire R, Dupont JC. Etude anatomique des myocardiopathies d'apparence primitive. Statistique française portant sur 134 observations. Arch Mal Coeur 1972; 65: 65-73.

2 Reeder GS, Tajik AJ, Seward JB. Detection of left ventricular thrombus with two-dimensional echocardiography (abstract). Circulation 1979; 59-60, suppl 11: 19.

3 Miller RD, Jordan RA, Parker RL, Edwards JE. Thrombo-embolism in acute and in healed myocardial infarction. II-Systemic and pulmonary arterial occlusion. Circulation 1952; 6: 7-15.

4 Fletcher AP, Biederman O, Moore D, Alkjaersig N, Sherry S. Abnormal plasminogen-plasmin system activity (fibrinolysis) in patients with hepatic cirrhosis: its cause and consequences. F Clin Invest 1964; 43: 681-95.

5 Pises P, Bick R, Siegel B. Hyperfibrinolysis in cirrhosis. Am $\mathcal{F}$ Gastroenterol 1973; 60: 280-9.

6 Mikell FI, Asinger RW, Sharma B, Francis G, Hodges $M$. Serial evaluation of left ventricular thrombi (LVT) by two-dimensional echocardiography (2 DE): effect of anticoagulant therapy (abstract). Circulation 1979; 59-60, suppl II: 19.

7 Meltzer RS, Guthaner D, Rakowski H, Popp RL, Martin RP. Diagnosis of left ventricular thrombi by twodimensional echocardiography. $B r$ Heart $\mathcal{F}$ 1979; 42: 261-5.

Requests for reprints to Dr Julien Bensaid, Hôpital Universitaire Dupuytren, 2 avenue Alexis Carrel, 87000 Limoges, France. 